\title{
An Ounce of Prevention is Worth a Pound of Cure: Ergonomics in Dental Practice
}

\author{
${ }_{1}$ Praveenkumar Ramdurg, ${ }^{2}$ Vijaylaxmi Mendigeri, ${ }^{3}$ Surekha Puranik
}

\begin{abstract}
Dentists and dental hygienists are at risk for work-related musculoskeletal disorders compared to the general population. The most frequent injuries occur in the spine (neck and back), shoulders, elbows and hands. While specific procedures place the clinician at increased risk for finger and hand injuries, poor posture is a risk factor with all procedures. Sitting in an appropriate chair, using magnification for visualization, and the selection of ergonomically-friendly equipment are essential for the health of dental clinicians. Ergonomics is the science of designing jobs, equipment and workplaces to fit workers. Proper ergonomics design is necessary to prevent repetitive strain injuries, which can develop over time and can lead to long term disability. This article includes musculoskeletal disorders (MSDs) and the signs, symptoms and risk factors of these types of injuries, so that one can be aware of developing problems and can change his /her approach to work or alter the workstation setup to prevent further injury. The article discusses the applications of ergonomics in dental clinic set up and offers different exercises to work with comfort, efficiency and ease.
\end{abstract}

Keywords: Ergonomics, Musculoskeletal disorders, Work station, Exercise, Risk factors.

How to cite this article: Ramdurg P, Mendigeri V, Puranik S. An Ounce of Prevention is Worth a Pound of Cure: Ergonomics in Dental Practice. J Postgrad Med Edu Res 2015;49(1):37-42.

Source of support: Nil

Conflict of interest: None

\section{INTRODUCTION}

Visit any shopping center and you will find a number of products labeled, 'ergonomic,' from can openers bearing squishy handles, to dog food bowls on elevated platforms so that spot does not need to stoop for breakfast. What does 'ergonomics' mean and why should dental professionals care?

In Greek, 'Ergo,' means work and, 'Nomos,' means natural laws or systems. Ergonomics, therefore, is an

\footnotetext{
${ }^{1,2}$ Assistant Professor, ${ }^{3} \mathrm{Head}$

${ }^{1,3}$ Department of Oral Medicine and Radiology, PMNM Dental College and Hospital, Bagalkot, Karnataka, India
}

${ }^{2}$ Department of Orthodontics, PMNM Dental College and Hospital, Bagalkot, Karnataka, India

Corresponding Author: Praveenkumar Ramdurg, Assistant Professor, Department of Oral Medicine and Radiology, PMNM Dental College and Hospital, Bagalkot, Karnataka, India, Phone: 8861593975, e-mail: vijuortho@gmail.com applied science concerned with designing products and procedures for maximum efficiency and safety. ${ }^{1}$ It is also a study of the relationship among the personnel, equipment and environment in the work area. ${ }^{2}$ The International Ergonomics Association defines ergonomics as follows: Ergonomics is the scientific discipline concern with the understanding of interactions among human and other elements of a system, and the profession that applies theory, principles, data and methods to design in order to optimize human well being and overall system performance. Ergonomics first entered the modern lexicon when Wojciech Jastrzebowski used the word in his 1857 article 'The Outline of Ergonomics, i.e. Science of Work, Based on the Truths Taken from the Natural Science'. The coining of term Ergonomics, however, is now widely attributed to British psychologist Hywel Murrell, at the 1949 meeting at the United Kingdom's admiralty, which leads to foundation of The Ergonomic Society. ${ }^{3}$

The musculoskeletal health of dental professionals has been the subject of numerous studies worldwide, and their focus has been on the pain experienced by the practitioner. Because their work area is narrow, performance of dental treatment results in a very inflexible work posture. ${ }^{4}$ Literaturesuggests that the prevalence of musculoskeletal disorders (MSDs) in dentist, dental hygienists and dental students ranges between 64 and $93 \%{ }^{5}$ Some other studies indicate that back, neck, and shoulder or arm pain is present up to $81 \%$ of dental operators. ${ }^{6}$ Researchers have found symptoms of discomfort for dental workers occurred in the wrists/hands (69.5\%), neck (68.5\%), upper back $(67.4 \%)$, low back $(56.8 \%)$ and shoulders $(60.0 \%){ }^{7}$

\section{WHAT ARE MSDs?}

Musculoskeletal disorders (MSDs) are described as disorders of the muscles, nerves, tendons, ligaments, joints, cartilage or spinal disks. The term 'work-related musculoskeletal disorders' (WMSDs) refers to MSDs that are made worse or longer lasting by work conditions. Dental professionals are among the workers who are more often susceptible to MSDs; they often cannot avoid prolonged static postures. Even in optimal seated postures, more than one half of the muscles of the body are contracted statically and there is a little movement of the vertebral joints. This may result in many pathologies, such as tendinitis, synovitis, tenosynovitis and bursitis (Table 1). ${ }^{8,9}$ Occupational 
diseases have not only physical, psychological, and social consequences, but also economic ${ }^{10}$ and security impacts when they reach a level of severity that directly affects work capacity, causing absences and early retirement. ${ }^{11}$

\section{RISK FACTORS FOR MSDs}

Musculoskeletal disorders are associated with a number of strains that are often combined in a single job, including strains related to holding various positions, force or repetitive movements. The problems vary according to the parts of the body affected. One or more factors may be involved. The presence of simultaneous strains increases the level of risk. Injuries may be sustained either by repeating the same movements or by a lack of movement.

Many ergonomic analyses of the work done by hygienists, dentists and dental assistants have made it possible to identify a certain number of risk factors.

- Awkward postures: Refers to positions of the body that significantly deviate from the neutral position while performing job tasks, such as working over head reaching, twisting, squatting or kneeling.

- Static postures: Static postures are defined by those which are held for a long period of time and may result in fatigue and injury. When a posture is held for a prolonged period of time there is a reduction in blood flow to the tissues. This results in a reduction of nutrient and oxygen supply with lactic acid and other metabolites accumulating, which can result in pain and tissue damage.

- Force: The amount of physical effort required to maintain control of equipment or tools, or to perform a task, such as heavy lifting, pushing, pulling or carrying.

- Repetitive movements: The risk of developing an MSD increases when same or similar parts of the body are used continuously, with few breaks. Highly repetitive tasks can lead to fatigue, tissue damage, discomfort, and, eventually injury. This can occur even if the level

Table 1: Understanding musculoskeletal disorders

\begin{tabular}{l}
\hline Some signs of MSDs \\
- Decreased range of motion \\
- Loss of normal sensation \\
- Lecreased grip strength \\
- Loss of normal movement \\
Some symptoms of MSDs \\
- Excessive fatigue in the shoulders and neck \\
- Tingling, burning, or other pain in arms \\
- Weak grip, cramping of hands \\
- Clumbiness in fingers and hands \\
- Hypersensitivity in hands and fingers \\
\hline
\end{tabular}
MSDs: Musculoskeletal disorders of force is low and the work postures are not awkward. Repetitive motions are extremely prevalent in clinical practice, particularly when performing scaling, root planning and polishing.

- Contact stress: Results from occasional, repeated, or continuous contact between sensitive body tissues and hard or sharp objects like resting the wrist on the edge of a desk, or tool handles pressing into palms. ${ }^{12-14}$

\section{APPLICATION OF ERGONOMICS}

Through ergonomic advances made over the years, dental professionals have been able to modify and optimize their working environments. Ergonomic improvements in work station layout, seating, selection of instruments, magnification and lighting have offered a proactive measure for ensuring a proper balance between job requirements and worker capabilities.

\section{Work Station Layout}

According to ergonomists, a person's work area should be close to and in front of him/her. A work area that respects the length of the arms is safe for the shoulders, neck and back. As can be seen in the following figure, the usual work area should be within the length of the forearm, or $25 \mathrm{~cm}$ (10 inches) (Fig. 1). ${ }^{15}$

To be able to work behind the patient's head (12:00 position), the dentist and hygienist have to be able to move easily between the back of the patient's chair and the rear counter or wall of the room. A minimum of $46 \mathrm{~cm}$ (18 inches) is necessary. ${ }^{16}$

Instruments are placed above the patient so that the distance for the clinician is minimized and there is significant reduction in his neck and left shoulder pain.

Negatoscope should be installed in front and on the dominant side. So, it makes possible to maintain the neck, the upper and lower back in a straighter position.

A counter or table should be placed on the dominant side to allow taking notes without twisting the body.

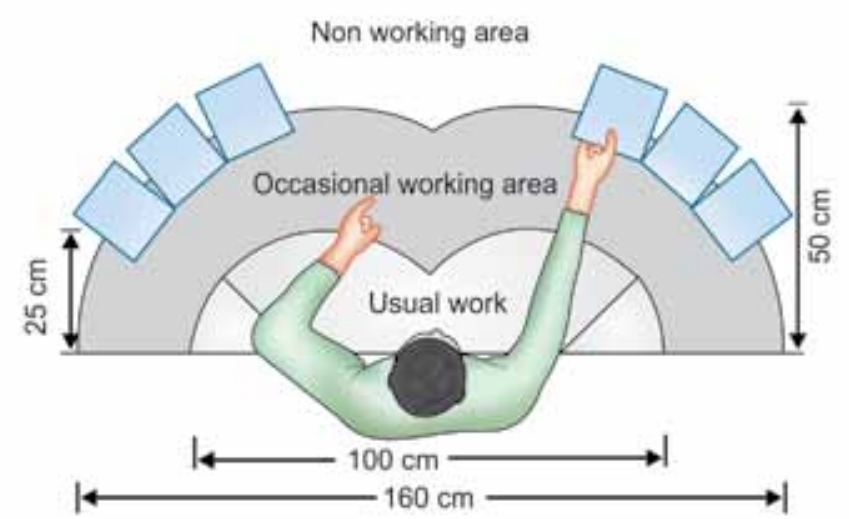

Fig. 1: Work station layout 


\section{Operator Chair}

For right-handed clinicians, working in the range from 7 to 9 o'clock is commonly associated with twisting of the trunk and neck as well as working with an elevated elbow posture in order to gain access. The mirror image ( 3 to 5 o'clock) is equally problematic for left-handed clinicians. In an attempt to reduce such postural deviations a conservative range from 10 o'clock to approximately 12:30 is preferred.

The risk for low-back pain is associated with work undertaken for prolonged periods of time in a seated position. Continual seating for a prolonged period results in activation of the upper and lower erector spinae muscles and in significantly greater low-back compressive loading in the lumbar spine region. ${ }^{17}$

Posture varies depending on the dental stool selected, so careful selection is crucial. The dental stool must fit correctly; it must offer neutral back, neck and shoulder support for optimal posture; must be at the correct height and tilt; and must offer optional arm and elbow support. Important design considerations include the back rest, height of the stool cylinder and armrests.

- Backrest: Back support is obtained by selecting a chair with a backrest that can be correctly adjusted for height and angulation. Lumbar support is helpful in avoiding any damaging spinal compression and muscular activity, by maintaining an ergonomic spinal curve of the seated person (Fig. 2). ${ }^{6}$

- Height of the stool cylinder: The height of the stool from the floor to the base of the seat is critical. If the stool is too high, it will cause the operator to perch on the edge of the seat, losing contact with the backrest of the chair. If too short, the clinician's pelvis will tend to roll backward, causing flattening of the lumbar spine (Fig. 3). ${ }^{6}$

- Armrests: Offer benefits by providing support during procedures. Shoulder support is aided by armrests, which help prevent back, shoulder and neck pain. Armrests are particularly useful if the clinician is staying in one position for an extended period of time. ${ }^{18}$

\section{Patient Chair}

When seating a patient optimal results will be achieved when their oral cavity is positioned at a height equal to the mid chest level of the clinician. ${ }^{19}$ Positioning the oral cavity above mid chest level will limit vantage and increase the rate of shoulder fatigue. On the other hand, positioning the oral cavity below the recommended height will result in non-neutral working postures including over declination of the head, forward and/or lateral bending of the torso, and inability of the clinician to access free movement in the clock positions.
The patient's head must be at the end of the headrest so that the clinician can keep his/her back supported on the lumbar support and also limit forward flexion of back and neck.

Sling or low profile arm rests should be incorporated to help the clinician to work in 8:00 to 10:00 positions without hitting their knees on a fixed metal arm rest.

Large knobs should be absent. They hit the edge of operator chair, preventing close positioning.

Finally, when the patient is properly positioned; your shoulders, elbows, and wrists should be in a neutral position, meaning that:

- Your upper arms are close to your body.

- Your elbow/forearm angle is close to $90^{\circ}$.

- Your wrists are in line with the forearm with no more than 20 to $30^{\circ}$ extension.

\section{Rheostat Positioning}

Place it close to the operator so that the knee is at about 90 to $100^{\circ}$ angle. If placed outside this zone, the dentist must shift weight to one side, leading to asymmetrical stresses on back, hence low back pain. Switch it from one foot to another 2 to 3 times a day.

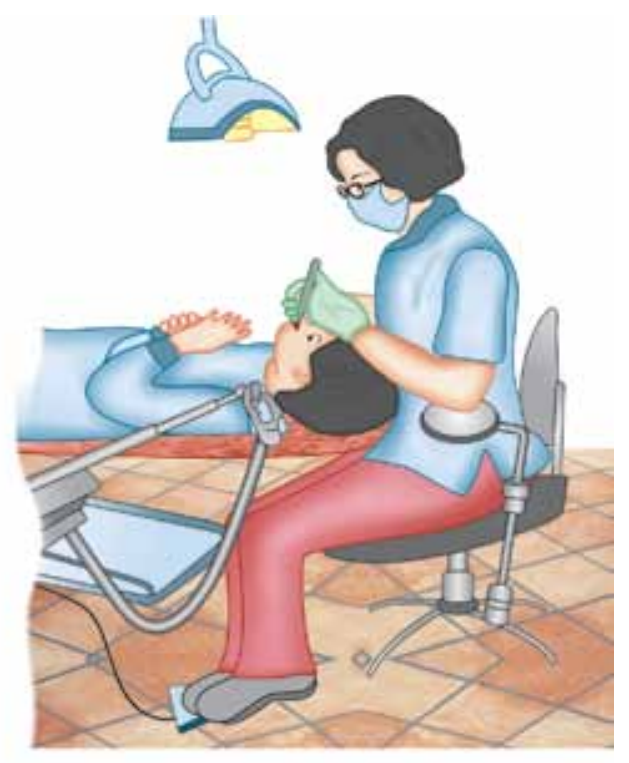

Fig. 2: Lumbar support

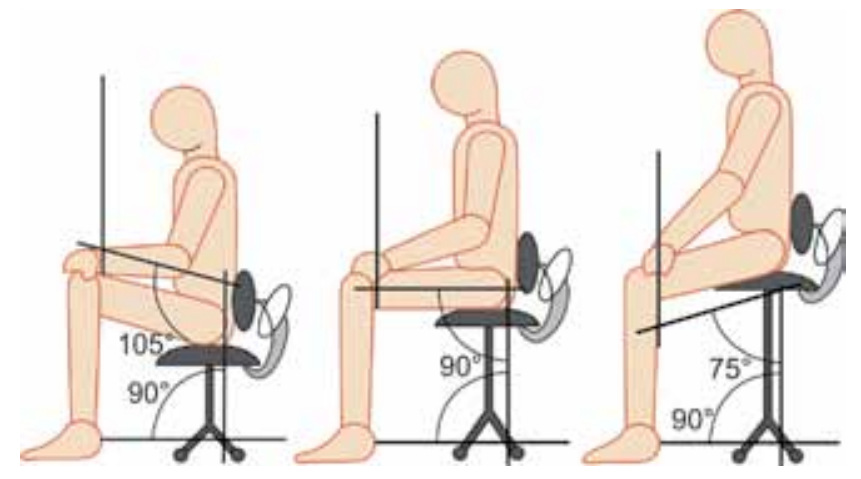

Fig. 3: Height of the stool cylinder 

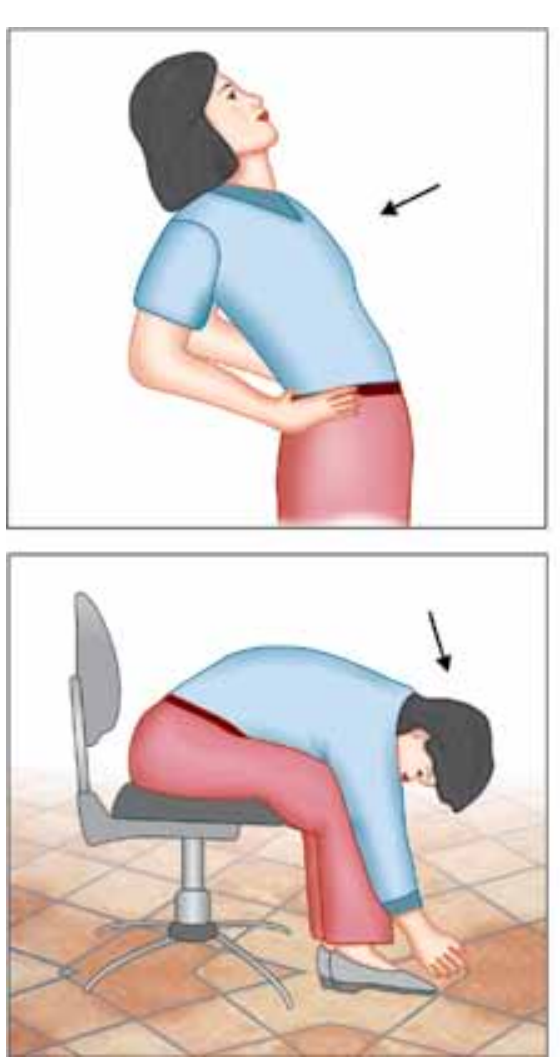

\section{Lighting}

Light positioning is a critical factor affecting clinician's posture during clinical operation. The goal of proper lighting is to produce even, shadow-free, color-corrected illumination concentrated on the operating field. Typically, a single light source can provide sufficient unshadowed viewing for a supine patient. For both mandibular and maxillary treatment, the light source should be directly above and slightly behind the patient's oral cavity. This not only serves to increase visibility but can also reduce awkward working postures. ${ }^{20}$

\section{Instrumentation}

The design of dental instrumentation can play a key role in the prevention of negative health effects for its users. Dental clinicians are typically responsible for selecting and maintaining their own instruments and equipment. The goal of proper instrument selection should be to reduce force exertion while allowing for neutral joint positioning. Critical areas to consider when selecting new or evaluating existing instruments, which is summarized $^{21}$ in Table 2.

Additional tips for instrument selection are as follows:

- Hollow or resin handles are preferred

- Round, textured/grooves (knurled) or compressible handles are preferred

- Color-coding may make instrument identification easier.

- Carbon steel construction (for instruments with sharp edges) is preferred.

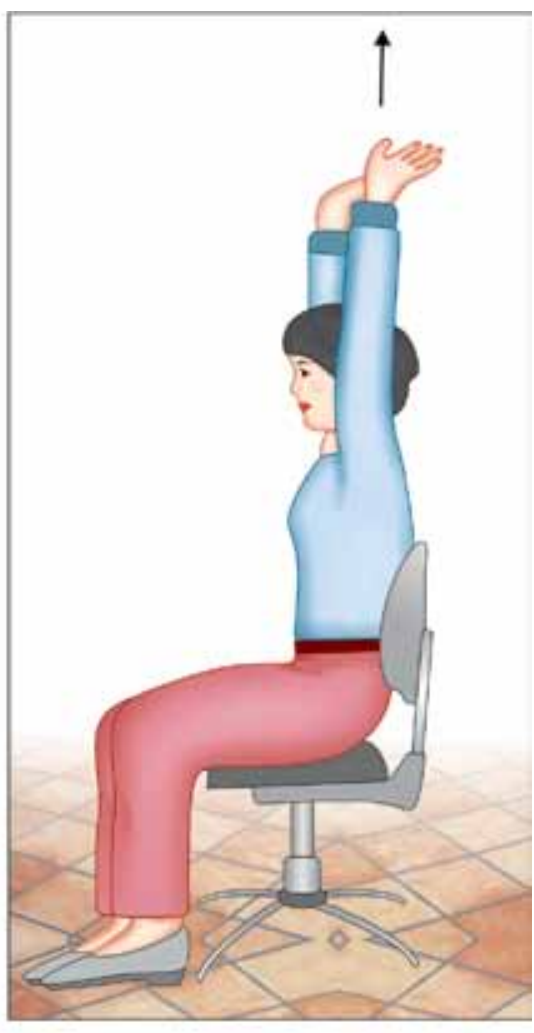

(n)

Fig. 4: Body stretching exercise

\section{DENTAL HAND PIECES}

When selecting hand pieces, look for the following:

- Lightweight, balanced models (cordless preferred)

- Sufficient power

- Built-in light sources

- Angled vs straight-shank

- Pliable, lightweight hoses (extra length adds weight)

- Swivel mechanisms

- Easy activation

\section{ULTRASONIC TOOLS}

While ultrasonic tools can serve to reduce prolonged pinch gripping they do expose the clinician to hand-arm vibration. Research has been controversial regarding the relationship between the use of ultrasonic scalers and the development of musculoskeletal problems. While some studies indicate that prolonged use of this equipment can be hazardous due to the negative effects associated with vibration, other researchers suggest that its use is preferable to the heavy hand forces experienced during manual scaling. As result, educators suggest using ultrasonics for heavy calculus build-up, but limiting the overall usage of this vibrating tool. ${ }^{22}$

\section{CORD MANAGEMENT}

The added weight of cords can often influence the level of muscle fatigue experienced by a clinician. Additionally, coiled hoses can cause the hands and wrists to do more 
Table 2: Instrumentation

\begin{tabular}{|c|c|}
\hline $\begin{array}{l}\text { Handle shape and } \\
\text { size }\end{array}$ & $\begin{array}{l}\text { - Dental instrument diameter ranges from } 5.6 \text { to } 11.5 \mathrm{~mm} \text {. Larger handle diameters reduce hand muscle load } \\
\text { and pinch force. } \\
\text { - 'No. 4' handle lessens pinch gripping and can be purchased for most instruments. } \\
\text { - A round handle, compared to a hexagon handle will reduce muscle force and compression. }\end{array}$ \\
\hline Weight & - $\quad$ Lightweight instruments (15 gm or less) help reduce muscle workload and pinch force (Dong, 2006). \\
\hline $\begin{array}{l}\text { Balance/ } \\
\text { maneuverability }\end{array}$ & $\begin{array}{l}\text { - The instrument should be equally balanced within the hand so that the tendency to deviate the wrist is reduced. } \\
\text { Balancing an instrument is improved using a third digit rest compared a fourth digit rest since it does not engage } \\
\text { the wrist as much while guiding and positioning the hand piece. The second digit (index finger) can detect very } \\
\text { fine movements and should be placed close to the operating point. By not using the fourth digit as a stabilizer } \\
\text { of the hand piece reduces the number of fingers in the oral cavity, improves the ability to position instruments, } \\
\text { and involves as few joint segments as possible thereby improving the degree of control and providing enhanced } \\
\text { tactile ability. }\end{array}$ \\
\hline Ease of operation & $\begin{array}{l}\text { The easier it is to operate a tool, the better. Less time is spent searching for buttons, thereby reducing the risk } \\
\text { of error. Less time is also spent learning how to use the device. Simple activation is also important, such as } \\
\text { using a foot pedal or handle turn to activate the tool as they do not require the operator to hold a button in a } \\
\text { sustained pinch grip for extended periods of time. }\end{array}$ \\
\hline Sharpness & $\begin{array}{l}\text { - As a tool becomes dull, additional force is required to perform tasks. As a result, it is important to maintain } \\
\text { sharpness of the instruments. }\end{array}$ \\
\hline Texture & $\begin{array}{l}\text { - Knurled handles such as diamond-shaped or crisscross patterns serve to reduce pinch grip force due to an } \\
\text { increase in tactile sensation as a result of the knurl. }\end{array}$ \\
\hline
\end{tabular}

work if the coils have too much resistance to deformation. So, it is recommended that retractable or coiled hoses be avoided and replaced with a pliable hose which consists of a swivel mechanism in the barrel.

\section{FINGER RESTS}

In addition to increasing hand stabilization, the use of two-finger rests has shown musculoskeletal advantages when performing scaling procedures. When researchers examined three different finger positions (no rest, 1-finger rest, and 2-finger rests) they found significant reductions in thumb pinch forces and muscle activity when using rests. More specifically, two-finger rests always produced these reductions, as compared to not using any finger rests, while one finger rest reduced thumb pinch force and muscle activity most of the time. ${ }^{21}$

\section{GLOVES}

Gloves are commonly worn due to universal precautions. Gloves must be of proper size, lightweight and pliable. Poor fitting gloves can cause pain in the hands, particularly at the base of the thumb. This is often due to compression of the tissues when gloves are either too small or too loose as 'bunching' occurs. When used for extended periods of time, gloves must be pulled into a working position, which may compress the back of the hand, strain muscles at the base of the thumb, and reduce blood flow to the hand. Properly fitted gloves should fit hands and fingers snugly, should not feel tight across the wrists and be hand-specific (right vs left-hand design).

\section{MAGNIFICATION SYSTEM}

Main goal of the magnification is to improve neck posture and to provide clearer vision. Use of normal scopes necessitates $20^{\circ}$ forward head bending which leads to flatting of low back curve and hence low back pain. In contrast, procedure scopes utilizes $0^{\circ}$ forward head bending and extraoral camera to display image on a liquid-crystal display (LCD) screen, hence, better vision. ${ }^{23}$

\section{EXERCISES FOR CLINICIAN}

Ergonomics problems in dentistry can be reduced by implementing various strategies which are discussed above. Dentists should also perform specific exercises for the trunk and shoulder girdle to enhance the health and integrity of the spinal column; stretching exercises for the hands and head and neck; maintain good working posture; optimize the function of the arms and hands; and prevent injuries. ${ }^{6}$ The following exercises can be practiced and performed by clinician on a regular basis in order to prevent MSDs.

\section{BODY STRENGTHENING EXERCISES}

Stretching and strengthening the muscles that support the back and neck and those used in the forearm, wrist, and hand will help them remain strong and healthy (Fig. 4). ${ }^{6}$

\section{HAND EXERCISES}

Slowly open and close hands from a completely open position, to a completely closed position, which ends with your fingers tucked into your palm; press the palms 
of your hands together and then relax them; gently pull and relax each finger on each hand separately; cross the wrists and gently stretch and relax. ${ }^{2}$

\section{NECK EXERCISES}

Relax shoulders and tuck the chin into the neck, then raise the head back; tilt head to the side as if trying to touch ear to the shoulder; repeat on other side. ${ }^{2}$

\section{BACK EXERCISES}

A 'full back release' should be practiced. Relax the neck, roll down slowly letting the arms and head fall between the legs; hold position for a while; raise slowly by contracting stomach muscles and rolling up, bringing the head up last. ${ }^{2}$

\section{SHOULDER EXERCISES}

Raise shoulders up toward the ears and rotate first in clockwise direction and then in anticlockwise direction. ${ }^{6}$

\section{CONCLUSION}

Every dental care facility has an opportunity for ergonomic improvement. While employers should always be seeking ways to modify and optimize their workplace to reduce the likelihood of injury, dental professionals need to pay attention to body symptoms in order to make changes that will prevent long-term problems. As a result, ergonomics should be a continuous and proactive measure for ensuring the proper fit between people and their working environment.

\section{REFERENCES}

1. American Dental Association INFOpak. Ergonomics for Dental Students. ADA INFOpak 2008;1-4(s).

2. Russell JG. Ergonomics in the dental surgery. J Soc Occup Med 1973 Oct;23(4):128-131.

3. Lehto TU, Helenius HY, Alaranta HT. Musculoskeletal symptoms of dentists assessed by a multidisciplinary approach. Community Dent Oral Epidemiol 1991 Feb;19(1):38-44.

4. Bramson JB, Smith S, Romagnoli G. Evaluating dental office ergonomic risk factors and hazards. J Am Dent Assoc 1998 Feb;129(2):174-183(s)

5. Hayes M, Cockrell D, Smith DR. A systemic review of musculoskeletal disorders among dental professionals. Int J Dent Hyg 2009 Aug;7(3):159-165.
6. Valachi B, Valachi K. Mechanisms leading to musculoskeletal disorders in dentistry. J Am Dent Assoc 2003 Oct;134(10): 1344-1350.

7. Anton D, Rosecrance J, Merlino L, Cook T. Prevalence of musculoskeletal symptoms and carpal tunnel syndrome among dental hygienists. Am J Industrial Med 2002;42(3):248-257.

8. Carvalho MV, Cavalcanti FI, Miranda HF, Soriano EP. Partial rupture of supraspinous tendon in a dentist: a case report. FIEP Bull 2006;76:131.

9. Doorn JW. Low back disability among self-employed dentists, veterinarians, physicians and physical therapists in The Netherlands. Acta Orthop Scand Suppl 1995 June; 263(Suppl):1-64.

10. Wunsch Filho V. The Brazilian workers' epidemiological profile. Rev Bras Med Trab 2004;2(2):103-117.

11. Hill KB, Burke FJ, Brown J, Macdonald EB, Morris AJ, White DA, Murray K. Dental practitioners and ill health retirement: a qualitative investigation into the causes and effects. Br Dent J 2010 Sep 11;209(5):E8.

12. Rundcrantz BL, Johnsson B, Moritz U. Occupational cervicobrachial disorders among dentists. Analysis of ergonomics and locomotor functions. Swed Dent J 1991;15(3):105-115.

13. Rundcrantz BL, Johnsson B, Moritz U. Pain and discomfort in musculoskeletal system among dentist. A prospective study. Swed Dent J 1991;15(5):219-228.

14. Rundcrantz BL. Pain and discomfort in musculoskeletal system among dentist. Swed Dent J Suppl 1991;76:1-102.

15. Canadian center for occupational health and safety. Ergonomic infogram/E-A01;1998. p. 2-37.

16. Callaghan JP, McGill SM. Low back joint loading and kinematics during standing and unsupported sitting. Ergonomics 2001;44(3):280-294.

17. van Dieën JH, de Looze MP, Hermans V. Effects of dynamic office chairs on trunk kinematics, trunk extensor EMG and spinal shrinkage. Ergonomics 2001;44(7):739-750.

18. Parsell DE, Weber MD, Anderson BC, Cobb GW Jr. Evaluation of ergonomic dental stools through clinical simulation. Gen Dent 2000;48(4):440-444.

19. Belensky M. Human-centered ergonomics: proprioceptive pathway to occupational health and peak performance in dental practice, in Denise C. Murphy (under the dir of), Ergonomics and the Dental Care Worker, American Public Health Association, Washington; 1998. p. 288.

20. University of British Columbia. (2008). Dental Clinical Ergonomics: study module. Available at: www.dentistry.ubc.ca/ergo.

21. Dong H, Barr A, Loomer P, Laroche C, Young E, Rempel D. The effects of periodontal instrument handle design on hand muscle load and pinch force. J Am Dent Assoc 2006 Aug; 137(8):1123-1130.

22. Sanders MJ, Turcotte CA. Ergonomic strategies for dental professionals. Work 1997 Jan;8(1):55-72(18).

23. Rucker LM. Surgical magnification: posture maker or posture breaker? In: Murphy DC, editor. Ergonomics and the dental care worker. Washington, DC: American Public Health Association; 1998. p. 191-213. 